\title{
Quantification of phenolics, flavonoids and antioxidant activity of Tamarindus indica from selected areas in Tanzania
}

\author{
MOURICE MBUNDE, ROBINSON H. MDEGELA`, H.S. LASWAI, F.P. MABIKI \\ Department Veterinary Medicine and Public Health, Faculty of Veterinary Medicine, Sokoine University of Agriculture. P. O. Box 3021, Morogoro, \\ Tanzania. Tel.: +255 2326045 42; Fax.: +255 2326046 47, •email: mdegela@ suanet.ac.tz, rmdegela @yahoo.com
}

Manuscript received: 17 July 2017. Revision accepted: 4 January 2018.

\begin{abstract}
Mbunde M, Mdegela RH, Laswai HS, Mabiki FP. 2018. Quantification of phenolics, flavonoids and antioxidant activity of Tamarindus indica from selected areas in Tanzania. Biofarmasi J Nat Prod Biochem 16: 22-28. The objective of this study was to establish the quantities and antioxidant activity in fruits and leaves of Tamarindus indica L. collected from three agroecological zones of Tanzania represented by the Morogoro, Tanga, and Dodoma regions. Samples were examined for their total phenolic and flavonoid contents as well as their antioxidant activity. The total phenolic content showed a significant difference in all fruit and leaves extracts and ranged from $1994.4 \pm 530.77$ to $17874.67 \pm 5234 \mathrm{mg} \mathrm{GAE} / 100 \mathrm{~g}$. Similarly, the total flavonoid content in tamarind leaf and fruit extracts ranged from $880 \pm 609.45$ to $11483.11 \pm 2559.67 \mathrm{mg} \mathrm{CE} / 100 \mathrm{~g}$ dry weight. There was a significant difference between the antioxidant activity in the leaf $(54.39 \pm 0.13 \%)$ and fruit extracts $(40.11 \pm 0.03 \%)$. Tamarind leaf extracts exhibited significantly higher radical scavenging activity than fruit extracts. The antioxidant activity in fruit extracts expressed in percentage ranged between $29.27 \pm 0.06 \%$ and $40.11 \pm 0.03 \%$, while in leaf extracts, the activity ranged from $22.33 \pm 0.08 \%$ to $54.39 \pm 0.13 \%$. The radical scavenging activity from Coastal leaf extracts had the highest activity, followed by Eastern leaf extracts and lastly, Central leaf extracts. The highest activity was shown in the fruit samples by Coastal fruit extracts, followed by Central fruit extracts, and Eastern fruit extracts were the least active. The values in the Ferric reducing power (FRAP) assay ranged between $6968 \pm 3655.91 \mu \mathrm{M} \mathrm{Fe}$ (II)/g and $76822.67 \pm 23259.9$ $\mu \mathrm{M} \mathrm{Fe}$ (II)/g for leaves and fruits dry mass, respectively. These values correspond to the antioxidant activity, positively correlated with the total phenolic and flavonoid contents. Geographical location and climatic conditions have been reported to have enormous effects on the amount and activity of antioxidants available in both tamarind leaves and fruits. Findings from the study indicated that tamarind could be utilized as a cheap source of antioxidants. However, more agronomic studies should be considered to confirm the effects of agroecological differences on antioxidant activity.
\end{abstract}

Keywords: Antioxidant activity, flavonoids, phenolics, Tamarindus indica

\section{INTRODUCTION}

Oxidation reactions that occur mainly in the human body are likely to produce free radicals, bringing about various disorders, including atherosclerosis, ischemia, arthritis, reperfusion injury of many tissues, gastritis, and cancer (Seal 2011). To protect the cells, organs, and systems of the body against the deleterious effects of free radicals, humans have a highly sophisticated and complex antioxidant protection system that functions interactively and synergistically to neutralize free radicals (Percival, 1996). Antioxidants prevent the oxidative damage caused by free radicals in the body, as they can react with free radicals, chelate catalytic metals, and act as oxygen scavengers. The antioxidant compounds in the body are primarily obtained from external sources, mainly through the consumption of fruits and vegetables. The need for a supply of antioxidants becomes even more critical with increased exposure to free radicals originating from external sources, such as exposure to x-rays, cigarette smoking, ozone, air pollutants, and industrial chemicals (Dimitrios 2006; Kumar 2011).

Since ancient times, humans have depended on natural sources, especially plants, to protect against the effects of various diseases and improve their lifestyles. With technological advancement and recent research findings, it has been revealed that certain non-nutritive chemicals produced by plants, such as terpenoids, flavonoids, and other phenolic compounds, which were initially thought to be of no importance to human health, possess antioxidant properties (Seal 2011).

Antioxidant compounds have been searched in several types of plant materials, such as vegetables, fruits, leaves, barks, and roots, in the form of crude plant drugs. Polyphenolic compounds, which are dominant in antioxidant activity, are then found to be common in leaves, fruits, stems, and barks. In plants, these compounds are essential for normal growth development and defense against infection and injury (Seal 2012; Aires et al. 2013). Epidemiological reports proposed that dietary intake of natural products has proved to have a strong inverse correlation with the risk of developing cancers and coronary heart disease (Lako et al. 2007; Zidenberg-Cherr and Heneman 2008). Antioxidants in natural sources, especially fruits and vegetables, have created a high demand for natural products to control and treat various infections and diseases. Some chemically synthesized drugs claim to have undesirable side effects (Mayunzu et al., 2011). 
Tamarindus indica L., commonly known as tamarind, has a long history in traditional medicine throughout Africa and Asia (El-Siddig et al., 2006; Lourith et al., 2009). In Tanzania, this species is increasingly being used by society for juice making or as a vegetable. Modern medical science has also confirmed its laxative and diuretic properties. All morphological parts of $T$. indica can be used, from the fruit pulp and seed to the leaves, bark, and flowers. Ailments such as diarrhea, ulcers, jaundice, eye infections, and digestive problems can be treated with infusions, pastes, and powders from $T$. indica (Khairunnuur et al., 2009; De Caluwé et al., 2010). Herbal practices are still widely used wherever T. indica is accessible (Rudrappa 2009).

Numerous studies have reported tamarind as having high levels of vitamins; A, B, and C and organic acids like citric, ascorbic acids, tartaric and malic, and polyphenols flavonoids. These compounds are primarily responsible for potent antioxidant, hepatoprotective, and antimicrobial activity (Lamien-Meda et al., 2008; Lourith et al., 2009; Rodríguez-Amado et al., 2012).

Many wild fruits and leaves contain significant amounts of antioxidant compounds, essential in preventing various diseases (Javanmardi et al., 2003). The properties of antioxidants are mainly brought about by polyphenolic compounds such as flavonoids, anthocyanins, phenolic acids, and phenolic diterpenes. Tamarindus indica $\mathrm{L}$. is reported to contain many polyphenolic compounds with the potential for antioxidant activity (Pieta 1998). Nevertheless, the quantities of antioxidants may vary with geographical location (Aires et al., 2011; Mahmood et al. 2012). Despite the extensive utilization and availability of T. indica in most parts of Tanzania, little is known about the amount and activity of antioxidants from this plant.

Furthermore, there is limited information on comparative analysis of antioxidant compounds available in the wild tamarind from different agroecological zones of Tanzania. Thereby, this study was designed to fill the existing knowledge gap. Findings from the study would be useful in providing baseline information about the antioxidant and antioxidant capacity of $T$. indica.

The objectives of this research were: (i) To quantify the number of phenolics and flavonoid contents in leaves and fruit extracts of $T$. indica from the Coastal, Eastern, and Central zones of Tanzania. (ii) To determine the antioxidant activities of extracts from leaves and fruits of $T$. indica from the zones above Tanzania.

\section{MATERIALS AND METHODS}

\section{Description of areas where samples were collected}

This study involved sample collection from three different locations that fall in agroecological zones. Coastal zone (Tanga), Eastern Plateau and Mountain Blocks (Morogoro), and Central Plateau (Dodoma). The Coastal zone (Tanga) lies 500-1200 meters above sea level and has been developed over gneissic rocks. The region has poorly drained, flat, broad topographical depressions developed on young alluvium and strongly dissected areas of pronounced slopes, often rocky and severely eroded. Two main types of soils are available: sandy clay loams and sandy clays, and sands and loamy sands. The region is mostly infertile and lacks moisture acceptance properties due to a tendency for surface sealing. It experiences bimodal rainfall ranging from 700-1200 mm per annum (USDA 2005; Handeni 2008).

The Eastern Plateau and Mountain block, which encompasses the Morogoro region (Mvomero district), exhibits undulating plains to dissected hills and mountains and moderately fertile clay soil. The area experiences unimodal rainfall ranging from 800 to $1400 \mathrm{~mm}$ (USDA 2005; Mbogoni and Ley 2008).

The Central Plateau (Dodoma region) has undulating plains with rocky hills and low scarps. Its soil is drained with low fertility. The rainfall is unimodal and unreliable, ranging from 500 to $800 \mathrm{~mm}$ (USDA 2005).

\section{Study design}

This observational study design was adopted whereby samples were collected and taken to the laboratory to extract and analyze antioxidants. Samples were collected from three villages, namely Misima (Tanga), Doma (Morogoro), and Ntyuka (Dodoma), purposively selected from the three zones. The collection of the samples was done purposively based on the availability of tamarind species with mature fruits in certain areas. In each region, five samples (leaves and fruits from five tamarind trees) were taken from one village. The basis for the selection of each area was the climatic condition, i.e., semi-arid, woodland, and coastal climatic conditions.

\section{Materials \\ Equipment and apparatus}

Whatman no. 1 filter paper, UV-visible spectrophotometer (UNICO VIS1200 Version SS-1.24, United Products and Instruments, Inc.), bench centrifuge, Buchner funnel, separating funnel $(250 \mathrm{~mL})$, beakers $(250$ $\mathrm{mL})$, volumetric flask $(5,10,25,50 \mathrm{~mL})$, measuring cylinder $(5,10,25,50 \mathrm{~mL})$, conical flasks $(25 \mathrm{~mL})$, cuvettes, Eppendorf tips, micropipettes.

\section{Chemicals and reagents}

Methanol $\left(\mathrm{CH}_{3} \mathrm{OH}\right)$, ethanol $\left.\left(\mathrm{C}_{2} \mathrm{H}_{5} \mathrm{OH}\right)\right)$, hydrochloric acid (HCl), Folin Ciocalteu Reagent (FCR), TPTZ (2, 4,6tripyridyl-s-triazine), iron sulphate heptahydrate $\left(\mathrm{FeSO}_{4} 7 \mathrm{H}_{2} \mathrm{O}\right)$, iron chloride $\left(\mathrm{FeCl}_{3}\right)$, sodium carbonate $\left(\mathrm{Na}_{2} \mathrm{CO}_{3}\right)$, sodium hydroxide $(\mathrm{NaOH})$, sodium acetate $\left(\mathrm{CH}_{3} \mathrm{COONa}\right)$, sodium acetate buffer $\left(\mathrm{C}_{2} \mathrm{H}_{3} \mathrm{NaO}_{2} \cdot 3 \mathrm{H}_{2} \mathrm{O}\right)$, sodium nitrite $\left(\mathrm{NaNO}_{2}\right)$, aluminium trichloride $\left(\mathrm{AlCl}_{3}\right)$, standard Gallic acid, butylated hydroxytoluene (BHT), 1, 1-diphenyl-2-picryl-hydrazyl (DPPH), vitamin C (ascorbic acid) and catechin. All the chemicals used, including the solvents, were analytical grade and purchased from the University Suppliers. 


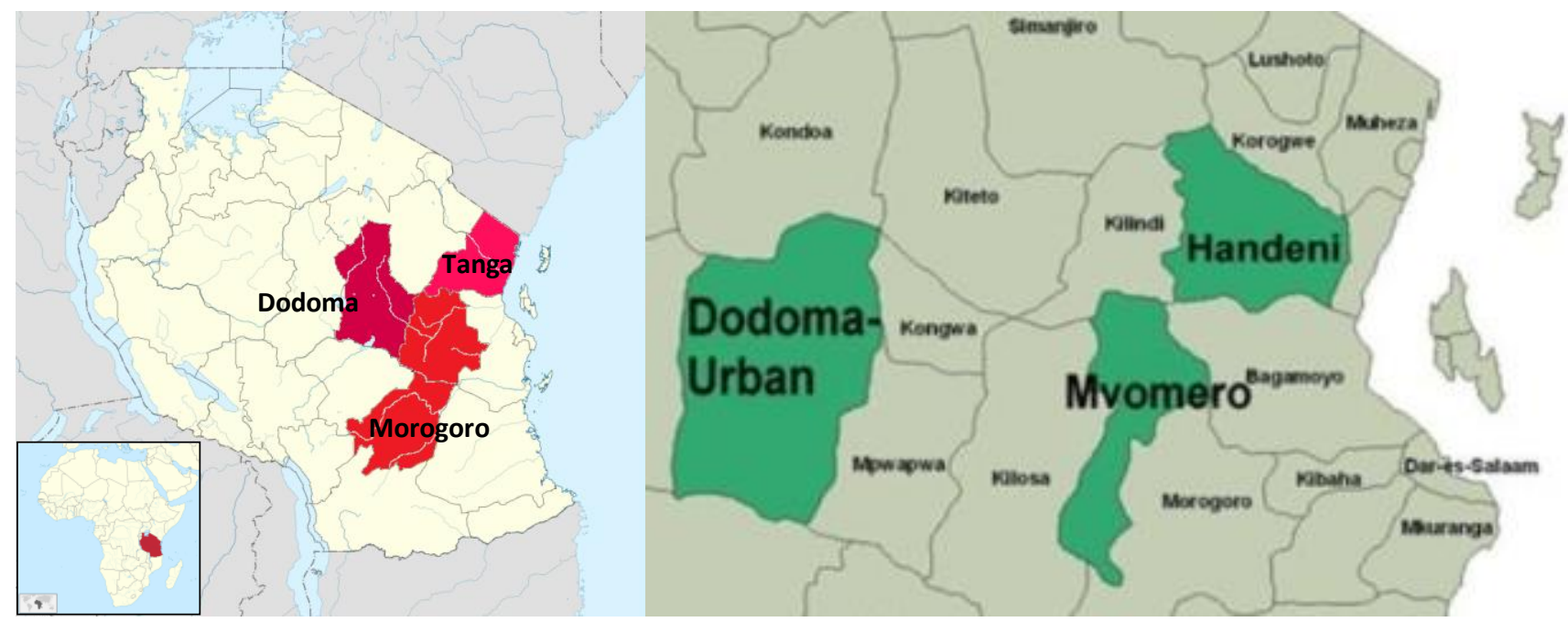

Figure 1. Map of the study area where samples were collected

\section{Methods}

\section{Collection of plant materials}

Fresh tamarind leaves and ripened fruits were collected from several populations of tamarind species in the selected agroecological zones (Plate 1). The Global Positioning System (GPS) was used to mark the coordinates and photographs of the plant taken at each location.

\section{Extract preparations}

The separated leaves were air-dried under the shade at room temperature $\left(30^{\circ} \mathrm{C}\right)$ and ground to a powder using a grinding machine. Ten grams of leaf powder (made from 2 $\mathrm{g}$ of individual sample) was extracted in $99.9 \%$ methanol for $48 \mathrm{hrs}$ at $30-33^{\circ} \mathrm{C}$. The fruits were peeled, and the pulps were separated from the seed (Ashafa et al., 2010). Ten percent pulp extract was prepared by soaking $10 \mathrm{~g}$ (made from $2 \mathrm{~g}$ of individual sample) of the fresh pulp in $100 \mathrm{~mL}$ of $99.9 \%$ methanol, then mixed thoroughly (Khairunnuur et al. 2009). The mixture was homogenized and allowed to stand for $48 \mathrm{hrs}$. Both fruit and leaf extracts were filtered through Whatman filter paper No.1. The filtrate was evaporated under reduced pressure at $40^{\circ} \mathrm{C}$ using a rotary evaporator. The crude extract obtained was stored at $-20^{\circ} \mathrm{C}$ until further analysis (Ashafa et al. 2010).

\section{Coding of samples}

The samples collected from three different zones were coded, as shown in Table 1.

Table 1. Coding of samples collected from three zones

\begin{tabular}{lcl}
\hline Code & Agro-ecological zone & $\begin{array}{l}\text { Source of tamarind } \\
\text { extract }\end{array}$ \\
\hline LVMR & Eastern zone & Leaves \\
FRMR & Eastern zone & Fruits \\
LVDM & Central zone & Leaves \\
FRDM & Central zone & Fruits \\
LVTA & Coastal zone & Leaves \\
FRTA & Coastal zone & Fruits \\
\hline
\end{tabular}

Note: LVMR = Morogoro leaf extract; FRMR = Morogoro fruit extract; LVDM = Dodoma leaf extract; FRDM = Dodoma leaf extract; LVTA $=$ Tanga leaf extract; FRTA $=$ Tanga fruit extract

\section{Determination of total phenolics content}

The concentration of total phenolics was measured according to the previously described method (Velioglu et al. 1998) with some modification whereby the diluted aqueous solution of each extract $(0.5 \mathrm{~mL})$ was mixed with Folin Ciocalteu reagent $(0.2 \mathrm{~N}, 2.5 \mathrm{~mL})$. The mixture was incubated at room temperature for 5 minutes and then added with sodium carbonate solution $(75 \mathrm{~g} / \mathrm{L}$ in water, two $\mathrm{mL}$ ). After incubation for 2 hours, the absorbance was read at $760 \mathrm{~nm}$. A standard calibration curve was plotted using Gallic acid (0, 25, 50, 75, 100, 125, 150, 175, 200, 225, 250 $\mathrm{mg} / \mathrm{L})$. The measurements were expressed as $\mathrm{mg}$ of Gallic Acid Equivalents (GAE)/100 g of fruit weight.

\section{Determination of total flavonoid contents}

Total flavonoid content was measured using a colorimetric assay (Zhishen et al. 1999). One $\mathrm{mL}$ aliquot of catechin standard solutions $(5,10,20,40,60,80,100,120$, $140,160,180,200 \mathrm{mg} / \mathrm{L})$ was placed in a test tube, then added with $4 \mathrm{~mL}$ of $\mathrm{ddH}_{2} \mathrm{O}$ and $0.3 \mathrm{~mL}(5 \%) \mathrm{NaNO}_{2}$. After $5 \mathrm{~min}, 1.5 \mathrm{~mL}(2 \%) \mathrm{AlCl}_{3}$ was added to the test tube and shaken to homogenize. Five minutes later, $2 \mathrm{~mL}$ of $1 \mathrm{M}$ $\mathrm{NaOH}$ was added to the mixture and shaken well. The absorbance of the mixture, pink in color, was read by spectrophotometer at $510 \mathrm{~nm}$ versus the prepared standard. Total flavonoid content in the fruit extract was expressed as $\mathrm{mg} / 100 \mathrm{~g}$ catechin equivalents (CE) (fresh weight basis). All samples were analyzed in triplicate.

\section{Determination of 1, 1-diphenyl-1-picrylhydrazyl scavenging activity}

Antioxidant activity of tamarind leaves and fruit extracts was determined using the stable DPPH (2, 2diphenyl-1-picrylhydrazyl) free radical scavenging as described elsewhere with some modification (Mensor et al. 2001). A four $\mathrm{mL}$ of $0.1 \mathrm{mM}$ DPPH solution was added into $2 \mathrm{~mL}$ of the solutions of Butylated hydroxyl toluene (BHT) in methanol at different concentrations $(25,50,75$, $100,125,150 \mathrm{mg} / \mathrm{L})$. The mixtures were shaken vigorously and incubated at room temperature for $30 \mathrm{~min}$. Next, $4 \mathrm{~mL}$ 
of DPPH was added to $1 \mathrm{~mL}$ of sample diluted with $2 \mathrm{~mL}$ of methanol, and the mixture was shaken vigorously and allowed to stand for $30 \mathrm{~min}$ at room temperature. The absorbance was read at $517 \mathrm{~nm}$ wavelength using a UVVIS spectrophotometer (UNICO VIS1200 Version SS-1.24) with Butylated hydroxyl toluene (BHT)was used as the reference. Lower absorbance values of the reaction mixture indicated a higher free radical scavenging activity. The solution was measured spectrophotometrically at 518 nm. The antioxidant activity (AA) was calculated as below: AA $\%=100-[(($ Absorbance of the sample-Absorbance of the blank)/ (Absorbance of the control)] x100 (Mensor et al. 2001).

\section{Determination of ferric reducing antioxidant power (FRAP)}

Ferric reducing antioxidant power (FRAP assay) was modified from the earlier study by Benzie and Strain (1996). The stock solutions included $300 \mathrm{mM}$ acetate buffer (3.1 $\mathrm{g} \mathrm{CH}_{3} \mathrm{COONa}$ and $\left.16 \mathrm{~mL} \mathrm{CH}_{3} \mathrm{OOH}\right)$, pH 3.6, $10 \mathrm{mM}$ TPTZ (2, 4, 6-tripyridyl-s- triazine) solution in 40 $\mathrm{mM} \mathrm{HCl}$, and $20 \mathrm{mM} \mathrm{FeCl} \cdot 6 \mathrm{H}_{2} \mathrm{O}$ solution. The fresh working solution was used in a ratio of $(10: 1: 1)$ by mixing acetate buffer, TPTZ, and $\mathrm{FeCl}_{3} \cdot 6 \mathrm{H}_{2} \mathrm{O}$. The temperature of the solution was increased to $37^{\circ} \mathrm{C}$ before use. A volume of $100 \mu \mathrm{L}$ extracts/standard was placed in a test tube and diluted with $300 \mu \mathrm{L}$ of distilled $\mathrm{H}_{2} \mathrm{O}$, then $2.85 \mathrm{~mL}$ of the FRAP solution was added and incubated for $30 \mathrm{~min}$. Readings of the colored product (ferrous tripyridyltriazine complex) were taken at $593 \mathrm{~nm}$. The standard curve lies between 100 and $700 \mu \mathrm{L} \mathrm{FeSO}_{4} \cdot 7 \mathrm{H}_{2} \mathrm{O}$. Results were expressed in $\mu \mathrm{M} \mathrm{Fe}$ (II)/g dried mass and compared with that of catechin.

\section{Data analysis}

Results were obtained from three replicate experiments. For each variable, treatment means were subjected to Analysis of Variance (ANOVA) and Duncan's Multiple Range Test (DMRT) of the CoHort CoStat software version 6.33. Significant differences were reported at $\mathrm{p}<0.05$.

\section{RESULTS AND DISCUSSION}

The antioxidant capacity of the different extracts derived from fruit and leaf and the ranking order for each assay are presented in Tables 2, 3, and 4 and Figures 2 and 3 . The variation observed in the number of polyphenolic contents in fruits harvested from three different agroecological zones might be attributed to the series of complex biochemical reactions during fruit ripening. The complex reactions affected the formation of phenolics, anthocyanins, flavonoids, carotenoids, and other volatile compounds leading to the development of final characteristics and distinct flavors of mature fruit (Gull et al. 2012).

\section{Total phenolics content}

The underlying mechanism of the method used in the phenolic determination (Folin-Ciocalteau assay) is an oxidation/reduction reaction according to the redox properties of antioxidant compounds that can react with the Folin-Ciocalteau Reagent (FCR), enhancing the measurement of phenolic concentration (Norshazila et al. 2010). Table 2 shows the phenolic content of tamarind extract and the ranking order for each extract.

This study demonstrated that phenolic compounds level in tamarind extracts from the three different agroecological zones varied significantly in both leaves and fruit extracts. In general, among the six sample extracts, the tamarind leaf and fruit extracts from the Coastal zone demonstrated the highest levels of phenolic content compared to the other zones. There was a high variation in phenolic content between tamarind morphological parts (i.e., fruits and leaves) in all cases. For instance, a tamarind leaf extract from the Coastal zone had a significantly higher concentration of phenolics (Table 2) than fruits from the same zone. The higher level of phenolics in tamarind fruits and leaves has not been reported as in the case of the present study except in seed extracts, as reported by Lourith et al. (2009). Depending on the solvent used, they found the contents to be approximately $713.24 \mathrm{mg}$ GAE/100 $\mathrm{g}$ to $63,691 \mathrm{mg}$ GAE/100 g. Compared to the present study, other groups also reported a low phenolics content in tamarind pulp $(957.33 \pm 13.20 \mathrm{~g}$ of GAE/100 $\mathrm{g}$ of fruit) (Lamien-Meda et al. 2008). Meanwhile, a study on the tamarind fruit done by Khairunnuur et al. (2009) reported lower levels of phenolic contents compared to the findings of this study, ranging from $19.21 \pm 0.29 \mathrm{~g} \mathrm{GAE} / 100 \mathrm{~g}$ in seed and $2.14 \pm 0.05 \mathrm{~g}$ $\mathrm{GAE} / 100 \mathrm{~g}$ in fruit.

This study further showed a significant variation in the total phenolic content in the tamarind leaf extract from the Coastal and Central zones (Table 2). No significant difference was observed in the total phenolic content of the tamarind leaf extract from the Eastern (Morogoro) and Coastal (Tanga) zone, likewise for fruit extracts from samples collected in the Central (Dodoma) and Eastern zones. These findings suggest that tamarind leaves and fruits growing in Tanzania contain more phenolic contents than those reported elsewhere, suggesting that Tanzania $T$. indica could have potent antioxidant activity.

The presence of higher concentrations of phenolic compounds in leaves could be explained by the change in the biochemical composition in the later stages of fruit ripening, i.e., different phenolic acids condense to form complex phenolic compounds such as tannins and lignin (Gull et al., 2012). Tamarind trees sampled in this study mostly had only younger leaves, thus supporting the argument by Rodríguez-Amado et al. (2012). They reported that younger leaves of tamarind bear higher phenolic compounds since the plant needs to protect itself from predators' attacks. Plant extract containing high levels of phenolic compounds may scavenge free radicals such as superoxide anion radicals and peroxy radicals in the human body and protect human cells or tissues against oxidative stress (Norshazila et al. 2010).

\section{Total flavonoid content}

The distribution of total flavonoid content (TFC) in tamarind leaves and fruit extracts concerning geographical 
regions is presented in Table 3. The level of flavonoids in tamarind leaf extracts except those samples collected from the Central zone were significantly higher than those of fruit extracts from all zones. In all extracts, fruits harvested from the Coastal zone had the lowest flavonoid content (Tables 3). Tamarind fruits extract from samples collected from the Central and Coastal zone did not show any significant differences in concentration of flavonoids among them. Likewise, the leaf extracts from samples collected from the Coastal and Eastern zones showed no significant difference in their flavonoid contents. However, a substantial difference in flavonoid content was found between the leaf and fruit extracts from the Coastal zone region, as demonstrated in Table 3.

The flavonoid content in the present study was higher than the values reported in other reports. Lamien-Meda et al. (2008) reported lower levels of flavonoids $(2.18 \pm 0.21$ $\mathrm{mg} \mathrm{QE} / 100 \mathrm{~g})$ in fruit methanolic extracts and (5.68 \pm 0.10 $\mathrm{mg} \mathrm{QE} / 100 \mathrm{~g}$ ) in fruit acetone extract tamarind growing in Burkina Faso. The presence of higher concentrations of flavonoid compounds in younger leaves compared to those in fully ripe fruits could be attributed to the fact that the later stages of fruit ripening exhibit different phenolic acids that may condense to form complex phenolic compounds such as tannins and lignin. Hence, due to changes in phenolic compounds with maturity, fully-ripe fruit possessed relatively lower amounts of total flavonoid contents (Gull et al. 2012). Concentrations of flavonoid compounds in younger leaves compared to the fruits may be attributed to the fact that flavonoids are responsible for color formation; therefore, most samples were found to have yellow and red colors (Plate 6), suggesting a higher level of flavonoids. The growing conditions could also influence differences in flavonoid contents of different samples of tamarind from different locations, the genetic make-up of the species, amount of precipitation, altitude, temperature, soil conditions, and availability of nutrients (Jaffery et al. 2003; Mahmood et al. 2012; RodríguezAmado et al. 2012). The above factors might have affected the concentration of flavonoids in fruit and leaf extracts tested by altering the composition of their phytochemicals.

On the other hand, it was detected that tamarind has a higher concentration of phenolics than flavonoids in both leaf and fruit extracts tested. Tamarind leaf extracts had significantly higher polyphenolic compounds (phenolics) and flavonoids than fruit extracts.

\section{Radical scavenging activity}

The DPPH test determines the antioxidant activity, which is based on the ability of the stable free radical 2,2diphenyl-1-picrylhydrazyl to react with hydrogen donors, including phenols (Lamien-Meda et al. 2008). The bleaching of 2,2-diphenyl-1-picrylhydrazyl by a test compound represents its capacity to scavenge free radicals generated independently from any enzymatic or transition metal-based system. Antioxidant compounds available in sample extracts react with DPPH, a stable free radical, to convert it to 1,1-diphenyl-2- (2,4,6-trinitrophenyl) hydrazine (Ali et al. 2010).
The bleaching of DPPH solution regularly increases with increasing sample fruit and leaf extracts in a given volume, as shown in Figure 3. The bleaching action of antioxidant compounds like the solution (Lamien-Meda et al. 2008). The antioxidant activity of the samples tested showed variation over the tested samples (Figure 3 ). The results showed that scavenging activity decreased in the following order: LVTA $<$ LVMR $<$ LVDM $<$ FRTA $<$ FRDM $<$ FRMR. This trend implied that tamarind growing in the Coastal zone had the highest reduction potential than in other zones. This observation reflected the concentration of phenolics and flavonoids observed in the sample extracts from the Coastal Zone.

There was a significant difference in the antioxidant activity between the extracts from the leaf $(54.39 \pm 0.13 \%)$ and that from the fruit $(40.11 \pm 0.03 \%)$. Radical scavenging activity observed in leaf and fruit extracts was correlated with the concentration of phenolics and flavonoids found in all the extracts, with a strong positive correlation between total phenolic content and radical scavenging activity $\left(\mathrm{R}^{2}=\right.$ 0.923). This correlation suggested that polyphenols are responsible for antioxidant activity. Lamien-Meda et al. (2008) underscored that variation in radical scavenging ability among the tamarind extracts over the regions can be brought by the difference in climate and solvent used.

Table 2. Total phenolics content (mg GAE/100 g) of tamarind leaf and fruit extracts collected from different agro-ecological zones in Tanzania $(\mathrm{n}=6)$

\begin{tabular}{lll}
\hline${ }^{\mathbf{2}}$ Code & $\begin{array}{c}\text { Agro-ecological } \\
\text { zone }\end{array}$ & \multicolumn{1}{c}{$\begin{array}{c}\mathbf{1}^{\mathbf{T}} \text { Total phenolics content } \\
(\mathbf{m g ~ G A E} / \mathbf{1 0 0} \text { g) }\end{array}$} \\
\hline LVMR & Eastern zone & $17874.67 \pm 5234^{\mathrm{a}}$ \\
LVTA & Coastal zone & $17799.25 \pm 4825.05^{\mathrm{a}}$ \\
LVDM & Central zone & $6144.6 \pm 2205.23^{\mathrm{b}}$ \\
FRTA & Coastal zone & $4755 \pm 1699.25^{\mathrm{b}}$ \\
FRMR & Eastern zone & $2073.33 \pm 287.39^{\mathrm{c}}$ \\
FRDM & Central zone & $1994.4 \pm 530.77^{\mathrm{c}}$ \\
\hline
\end{tabular}

Note: ${ }^{1}$ Values are mean \pm SD of 6 samples analyzed individually in triplicates. Values with superscripts significantly different at $(p<0.05)$ in leaf and fruits extracts. ${ }^{2} \mathrm{LVMR}=$ Morogoro leaf extract; FRMR = Morogoro fruit extract; LVDM = Dodoma leaf extract; FRDM = Dodoma leaf extract; LVTA = Tanga leaf extract; FRTA $=$ Tanga fruit extract

Table 3. Total flavonoid contents of tamarind leaves and fruit extracts from different agro-ecological zones in Tanzania $(n=6)$

\begin{tabular}{lll}
\hline \multicolumn{1}{c}{ 'Code } & $\begin{array}{c}\text { Agro-ecological } \\
\text { zones }\end{array}$ & \multicolumn{1}{c}{$\begin{array}{c}\mathbf{1} \text { Total flavonoid content } \\
(\mathbf{m g} \text { Ce 100/G Dry Wt })\end{array}$} \\
\hline LVTA & Coastal zone & $11483.11 \pm 2559.67^{\mathrm{a}}$ \\
LVMR & Eastern zone & $9853.33 \pm 6588.47^{\mathrm{a}}$ \\
LVDM & Central zone & $3957.33 \pm 390.82^{\mathrm{b}}$ \\
FRMR & Eastern zone & $2146.67 \pm 107.7^{\mathrm{bc}}$ \\
FRDM & Central zone & $1088 \pm 294.23^{\mathrm{c}}$ \\
FRTA & Coastal zone & $880 \pm 609.45^{\mathrm{c}}$ \\
\hline
\end{tabular}

Note: ${ }^{1}$ Values are mean \pm SD of 6 samples analyzed individually in triplicates. Values with superscripts significantly different at $(\mathrm{p}<0.05)$ in leaf and fruits extracts. ${ }^{2} \mathrm{LVMR}=$ Morogoro leaf extract; FRMR $=$ Morogoro fruit extract; LVDM = Dodoma leaf extract; FRDM = Dodoma leaf extract; LVTA = Tanga leaf extract; FRTA $=$ Tanga fruit extract 


\section{Ferric reducing activity}

The ferric reducing antioxidant potential (FRAP) assay was applied to examine the free radical scavenging capacities and the lowering possibilities of the antioxidant constituents of the tamarind extracts. This assay is usually based on the reducing power of a compound (antioxidant) and measures the reduction of $\mathrm{Fe}^{3+}$ (ferric iron) to $\mathrm{Fe}^{2+}$ (ferrous iron). As the ferric ion is reduced to a ferrous ion, the values in the FRAP assay express the corresponding concentration of electron-donating antioxidants (Ali et al., 2010).

Table 4 displays the FRAP values of tamarind leaf and fruit extracts. The antioxidant activity was found to vary among the extracts from different agroecological zones of Tanzania. The trend for the decrease in FRAP values or reduction potential among the extracts was LVTA< LVMR $<$ LVDM $<$ FRTA $<$ FRMR $<$ FRDM. When comparing the FRAP values among the extracts, it was found that tamarind leaf extracts collected from the Coastal zone had the highest FRAP values $(p<0.05)$, followed by leaf extracts from the Eastern zone (Table 4).

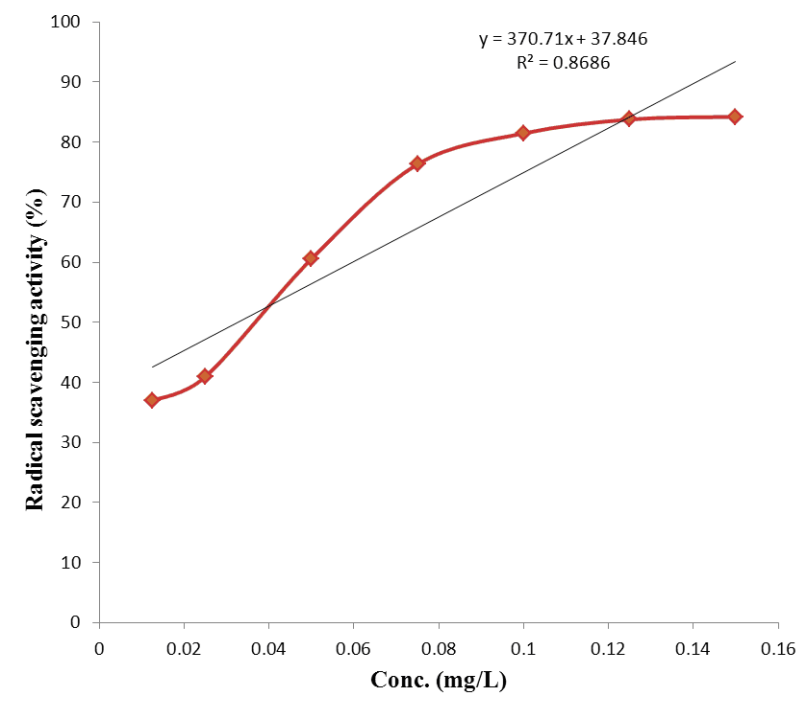

Figure 2. DPPH-free radical scavenging activity (RS \%) of butylated hydroxytoluene (BHT) used as standard

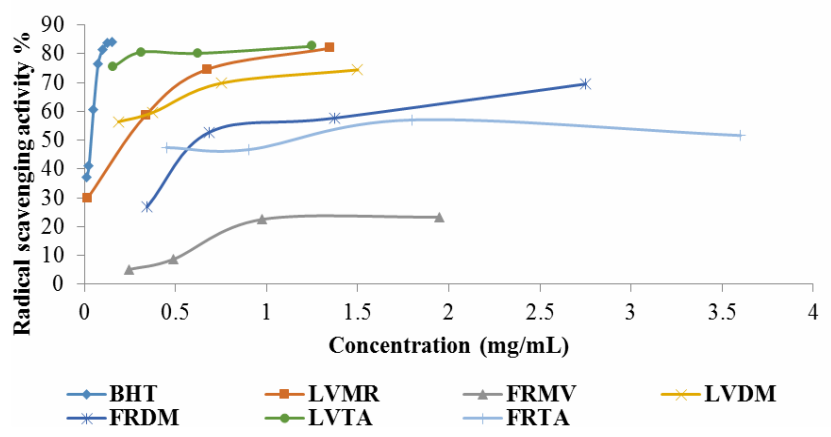

Figure 3. Effect of concentration of tamarind extracts in free radical scavenging activity. BHT $=$ Positive Control; LVMR = Morogoro leaf extract; FRMR = Morogoro fruit extract; LVDM = Dodoma leaf extract; FRDM = Dodoma leaf extract; LVTA = Tanga leaf extract; FRTA = Tanga fruit extract
Table 4. Ferric Reducing Antioxidant Power (FRAP) values of tamarind leaf and fruit extracts from different Agro-ecological zones in Tanzania $(\mathrm{n}=6)$

\begin{tabular}{lll}
\hline Code & Agro-ecological zones & ${ }^{1} \boldsymbol{\mu M}$ Fe (II)/g dry mass \\
\hline LVTA & Coastal zone & $76822.67 \pm 23259.9^{\mathrm{a}}$ \\
LVMR & Eastern zone & $32776 \pm 24506.66^{\mathrm{b}}$ \\
LVDM & Central zone & $8199.33 \pm 2929.49^{\mathrm{c}}$ \\
FRTA & Coastal zone & $6968 \pm 3655.91^{\mathrm{c}}$ \\
FRMR & Eastern zone & $5328 \pm 2945.96^{\mathrm{c}}$ \\
FRDM & Central zone & $3860 \pm 2377.57^{\mathrm{c}}$ \\
\hline
\end{tabular}

${ }^{1}$ Values are mean \pm SD of six samples analyzed individually in triplicates. Values with the superscripts significantly different at $(p<0.05)$ in leaf and fruits extracts. ${ }^{2} \mathrm{LVMR}=$ Morogoro leaf extract; FRMR = Morogoro fruit extract; LVDM = Dodoma leaf extract; FRDM = Dodoma leaf extract; LVTA = Tanga leaf extract; FRTA = Tanga fruit extract

Leaf and fruit extracts obtained from the Central zone did not show any difference between them but showed a significant difference $(\mathrm{p}<0.05)$ with the leaves from the Coastal and Eastern zone. There was a considerable difference in FRAP values $(76822.67 \pm 23259.9 \mu \mathrm{M} \mathrm{Fe}$ (II)/g dry mass) in leaf extracts from the Coastal zone compared with FRAP values of fruit extracts from the same location. Total phenolic and flavonoid content correlates with ferric reducing antioxidant activity. These results agreed with Khairunnuur et al. (2009), who found a significant difference between FRAP values of tamarind fruit and seed extracts. The impact of geographical factors on the antioxidant property has been shown by variations in FRAP values observed among tamarind extracts obtained from the three agroecological zones.

This study showed that the amount and activity of antioxidants were higher for samples from the Coastal zone (moderate temperature) than for samples from the Central zone (extreme temperature). This indicated the effect of the agroecological zone on the amount and activity of antioxidants available in both tamarind fruits and leaves. The Coastal zone (Tanga) and Eastern zone (Morogoro) were observed to possess favorable factors that promote the production of phytochemicals in tamarind as compared to the Central zone (Dodoma). These two zones (Tanga and Morogoro region) share the same geographical factors: temperature, soil type, and rainfall (USDA 2005). According to Gull et al. (2012), moderate temperature conditions $\left(25 / 30^{\circ} \mathrm{C}\right)$ are suitable for increasing antioxidant content. The authors further argued that plants growing in extreme cold $\left(18 / 12^{\circ} \mathrm{C}\right.$ ) or hot (above $35^{\circ} \mathrm{C}$ ) temperatures produce fruits and leaves with lower antioxidant content (Gull et al. 2012).

In conclusion, from the results, the amount of phenolics and flavonoid content of leaf extracts is higher than that of fruit extracts. Furthermore, there is variation in phenolics and flavonoid content amongst the three agroecological zones in which sample extracts obtained from the Coastal zone contained the highest amount of these polyphenols. Leaf extract from the Eastern and Coastal zone exhibited significantly higher antioxidant activity levels than extracts from the Central zone. Also, the leaf extracts showed higher radical scavenging activity than fruit extracts in the 
following orders LVTA $<$ LVMR $<$ LVDM $<$ FRTA $<$ FRDM $<$ FRMR, from high to low amounts, respectively. Antioxidant activity was positively correlated with the total phenolics and flavonoid contents. The polyphenols content and the mean DPPH and FRAP in all sample extracts differed significantly. This behavior is frequent in natural products due to variation that relates to climate, soil characteristics, and phenological stages of the plant, at the fructification stage. Phenolics and flavonoid compounds in leaves of the plants are higher in earlier growth stages, probably as a strategy of the plant to protect itself from the insects and predators' attacks.

\section{REFFERENCES}

Aires A, Fernandes C, Carvalho R, Bennett RN, Saavedra MJ, Eduardo ASR. 2011. Seasonal effects on bioactive compounds and antioxidant capacity of six economically important Brassica vegetables. Molecules 16: 6816-683.

Aires A, Marques E, Carvalho R, Rosa EAS, Saavedra MJ. 2013. Evaluation of biological value and appraisal of polyphenols and glucosinolates from organic baby-leaf salads as antioxidants and antimicrobials against important human pathogenic bacteria. Molecules 18: 4651-4668.

Ali MA, Devi LI, Nayan V, Chanu KHV, Ralte L. 2010. Antioxidant activity of fruits available in Aizawl market of Mizoram, India. Intl J Biol Pharmaceut Res 1 (2): 76-81.

Ashafa AOT, Grierson DS, Afolayan AJ. 2010. In Vitro Antioxidant activity of extracts from the leaves of Felicia muricata thunb. an underutilized medicinal plants in the Eastern Cape Province, South Africa. African J Trad Compl Altern Med 7 (4): 296-302.

Benzie IFF, Strain JJ. 1996. The ferric reducing ability of plasma as a measure of antioxidant power. Anal Biochem 239: 70-76.

De Caluwé E, Halamová K, Van Damme P. 2010. Tamarindus indica L. A review of traditional uses, phytochemistry, and pharmacology. Afrika Focus 23 (1): 53-83.

Dimitrios B. 2006. Sources of natural phenolic antioxidants. Trends Food Sci Technol 17: 505-512.

El-Siddig K, Gunasena HPM, Prasad BA, Pushpakumara DKNG, Ramana KVR, Vijayanand P, Williams JT. 2006. Tamarind, Tamarindus indica. Southampton Centre for Underutilized Crops, Southampton, UK.

Gull J, Sultana B, Anwar F, Naseer R, Ashraf M, Ashrafuzzaman M. 2012. Variation in antioxidant attributes at three ripening stages of guava (Psidium guajava L.). Fruit from different geographical regions of Pakistan. Molecules 17: 3165-3180.

Handeni District Council. 2008. District Investment Profile. Planning Office, Handeni, Tanga, Tanzania.

Jaffery EH, Brown AF, Kurilich AC, Keek AS, Matusheski N, Klein BP. 2003. Variation in content of bioactive components in broccoli. J Food Compos Anal 16: 323-330.

Javanmardi J, Stushno C, Locke E, Vivanco JM. 2003. Antioxidant activity and total phenolic content of Iranian Ocimum accessions. Food Chem 83: 547-550.

Khairunnuur FA, Zulkhairi A, Azrina A, Moklas MAM, Khairullizam S1, Zamree MS, Shahidan MA. 2009. Nutritional composition, in vitro antioxidant activity, and Artemia salina L. lethality of pulp and seed of Tamarindus indica L. Extracts. Malaysia J Nutr 15 (1): 65-75.
Kumar S. 2011. Free radicals and antioxidants: human and food system. Pelagia Research Library. Adv Appl Sci Res 2 (1): 129-135.

Lako J, Trenerry VC, Wahlqvist M, Wattanapenpaiboon N, Sotheeswaran S, Premierd R. 2007. Phytochemical flavonols, carotenoids, and the antioxidant properties of a wide selection of Fijian fruit, vegetables, and other readily available foods. Food Chem 101: 1727-1741.

Lamien-Meda A, Lamien CE, Compaoré MMY, Meda RNT, Kiendrebeogo M, Zeba B, Millogo JF, Nacoulma OG. 2008. Polyphenol content and antioxidant activity of fourteen wild edible fruits from Burkina Faso. Molecules 13: 581-594.

Lourith N, Kanlayavattanakul M, Chanpirom S. 2009. Free radical scavenging efficacy of tamarind seed coat and its cosmetics application. J Health Res 23 (4): 159-162.

Mahmood T, Anwar F, Abbas M, Saari N. 2012. Effect of maturity on phenolics (phenolic acids and flavonoids) profile of strawberry cultivars and mulberry species from Pakistan. Intl J Mol Sci 13: 45914607.

Mayunzu O, Shitanda D, Okalebo F, Simiyu F. 2011. Evaluation of antimicrobial and antioxidant properties of Mondia whytei roots extracts. The Annals of the University Dunarea de Jos of Galati Fascicle VI - Food Technology 35 (2): 27-32.

Mbogoni JDJ, Ley GJ. 2008. Characterization of Some Benchmark Soils of Morogoro Rural and Mvomero Districts, Mlingano. Agricultural Research Institute, Tanga, Tanzania.

Mensor LI, Menezes FS, Leitao GG, Reis AS, Dos-Santos T, Coube CS, Leitao SG. 2001. Screening of Brazillian plant extracts for antioxidant activity by the use of DPPH free radical method. Phytotherapy Res J 15: 127-130.

Norshazila S, Zahir IS, Suleiman KM, Aisyah MR, Rahim KK. 2010. Antioxidant levels and activities of selected seeds of Malaysian tropical fruits. Malaysia J Nutr 16 (1): 149-159.

Percival M. 1996. Antioxidants. Clinical nutrition insights. Nutrition 31 (1): 10-98.

Pieta P, Sieonetti P, Mauri P. 1998. Antioxidant activity of selected medicinal plants. J Agric Food Chem 44: 4487-4490.

Rodríguez-Amado J, Rosés PR, Escalona-Arranz CJ, Prada LA, González SGC. 2012. Standardization of the quality control parameters of the Tamarindus indica L. soft extract. Revista Cubana de Plantas Medicinales 17 (1): 108-114.

Rudrappa U. 2009. Tamarind nutrition facts. Available on line at [http://www.nutrition- and-you.com/Tamarind.html] site visited on $17 / 11 / 2012$.

Seal T. 2011. Antioxidant activity of some wild edible fruits of Meghalaya State in India. Adv Biol Res 5 (3): 155-160.

Seal T. 2012. Antioxidant activity of some wild edible plants of Meghalaya state of India: A comparison using two solvent extraction systems. Intl J Nutr Metab 4 (3): 51-56.

United States Department of Agriculture. 2005. Tanzania Agro-ecological Zones. Production estimates and crop assessment division foreign $\begin{array}{ll}\text { agricultural service. } & \end{array}$ [http://www.fas.usda.gov/pecad/highlights/2005/09/tanzania_2005/im ages/TZ_AE Z.htm] site visited on 20/11/2012.

Velioglu YS, Mazza G, Gao L, Oomah BD. 1998. Antioxidant activity and total phenolics in selected fruits, vegetables, and grain products. Amer Chem Soc 41: 4113-4117.

Zhishen J, Mengcheng T, Jianming W. 1999. The determination of flavonoid contents in mulberry and their scavenging effects on superoxide radicals. Food Chem 64: 555-559.

Zidenberg-Cherr S, Heneman K. 2008. Some Facts About Phytochemicals. Nutrition and Health Information Sheet. Cooperative Extension Center for Health and Nutrition Research Nutrition and Health Info Sheet, California. USA. 